\title{
Algemene tugmaatreëls in primêre skole van die Transvaalse Onderwysdepartement ${ }^{1}$
}

\author{
I.J. Oosthuizen \\ Departement Vergelykende Opvoedkunde en Onderwysbestuur \\ Potchefstroomse Universiteit vir CHO \\ POTCHEFSTROOM
}

\begin{abstract}
Amidst a worldwide trend of undisciplined behaviour, discipline in the classroom is regarded as crucial for pupils to learn effectively. In this article empirical data are analysed to determine the reasons for undisciplined behaviour among pupils and what point of view motivates teachers when applying general disciplinary methods. Apart from this, the article determines, by means of an analysis of empirical research, which of the general methods of control are favoured by teachers in the maintaining of order in the educative environment. It also analyses the pupil's responses to the administration of general methods of control at school.
\end{abstract}

\section{Oriëntering}

Wanneer die menings van didaktici en ander opvoedkundiges ontleed word, blyk dit duidelik dat die handhawing van gesag 'n conditio sine qua non vir opvoedkunde en onderwys is: opvoedende onderwys sonder die handhawing van gesag is nie moontlik nie. Lewis en Lovegrove (1984:98) sê in dié verband dat die handhawing van gesag is "so crucial, so basic to everything else in the classroom, that most educators agree: it is the one thing that makes or breaks teachers. If students don't stay on task, they don't leam". Baker (1985:486) voer aan dat "fighting students cannot learn. Students playing tag or being boisterous in the class room cannot learn". Wanorde kan volgens Heyns (1989:152) tot chaos lei wat weer die bestendigheidsontwrigting van die hele samelewing tot gevolg kan hê.

Die hedendaagse samelewing (i.c. die RSA) bevind hom egter in 'n gesagskrisis wat 'n wêreldfenomeen geword het (Griessel, 1975:55). Hierdie gesagskrisis raak

1 Dank word betuig an mnr. W.H. Bayliss wic se cmpiriesc navorsing hicrdic artikel moontlik gemaak het. 
uiteraard elke aspek van die samelewing - insluitend die opvoedende onderwys. In die VSA het die weerstand teen gesag in die skole met die voortspruitende ongedissiplineerdheid by die leerlinge, sulke afmetings aangeneem dat dit byvoorbeeld gedurende die periode 1968 tot 1984 elke jaar uitgewys is as die grootste enkele probleem in die Amerikaanse onderwys (Bauer, 1985:489). Shrigley (1986:65) sê byvoorbeeld dat hedendaagse onderwysergesag "seems muddled" en dat daar deur sommige persone beweer word dat onderwysers nie meer gesag dra nie. Hierdie weerstand teen gesag in die onderwys word ook in die RSA aangetref. Enkele Suid-Afrikaanse hofsake waarin die onderwysowerhede en/of onderwysers gedagvaar is vir beweerde onregmatighede by die uitoefening van gesag is die Staat v Lekgathe 19823 SA 104 (BT), die Staat v Mecuwis 19704 SA, Rex v Muller 19484 SA (O) en die saak van John Buckingham v Die Minister van Onderw'ys en Kultuur (1992 - ongerapporteer) (Altern, 1992:1).

$\mathrm{Na}$ aanleiding van hierdie probleme is besluit om vas te stel watter tugmaatreëls aangewend word by primêre skole en om dan die tugmaatreëls volgens sekere opvoedkundige kriteria te evalueer.

\section{Metode}

\subsection{Meetinstrument}

Om voorgemelde ondersoek te kon doen, is daar besluit om 'n posvraelys wat uit vier items bestaan op te stel. Die posvraelys is as die mees geskikte medium geag om die benodigde inligting te bekom. Nadat 'n eerste weergawe van die vraelys opgestel is wat aan 'n aantal skoolhoofde vir kommentaar voorgelê is, is enkele strukturele wysigings aangebring en is die finale vraelys opgestel. Toestemming is van die Direkteur van die Transvaalse Onderwysdepartement verkry om die vraelyste aan geselekteerde primêre skole te stuur vir voltooiing.

\subsection{Populasie}

Al die skoothoofde van primêre skole in die Transvaalse Onderwysdepartement het die populasie gevorn $(n=472)$. Uit hierdie populasie is $n$ ewekansige steekproef van $67,2 \%$ getrek $(n=317)$. Van die 317 vraelyste wat uitgestuur is, is 261 $(82,3 \%)$ terugontvang. Stedelike, semi-stedelike en plattelandse skole is proporsioneel verteenwoordigend versprei.

\subsection{Statistiese tegniek}

Ten einde die frekwensies en persentasies van die respondente te bepaal, is gebruik gemaak van die SAS-rekenarprogram (Statistical Analysis System). Die data is vir verwerking op die hooframrekenaar van die PU vir CHO ingesleutel 
IJ. Oosthuizen

en is verwerk met die die SAS-programpakket. By elke vraag is frekwensies en persentasies volgens die PROC FREC (frequency procedure) van SAS bepaal.

\section{Die resultate}

Tabel 1 Faktore wat moontlike oorsake van ongedissiplineerdheid is

\begin{tabular}{|c|c|c|c|c|c|c|c|c|c|}
\hline & \multirow{2}{*}{$\begin{array}{l}\text { Oorsake van ongedis- } \\
\text { siplineerdheid }\end{array}$} & \multicolumn{2}{|c|}{ Altyd } & \multicolumn{2}{|c|}{ Dikwels } & \multicolumn{2}{|l|}{ Selde } & \multicolumn{2}{|c|}{ Nooit } \\
\hline & & $\mathbf{f}$ & $\%$ & $\mathbf{f}$ & $\%$ & $\mathbf{f}$ & $\%$ & $\mathbf{f}$ & $\%$ \\
\hline $\mathbf{a}$ & $\begin{array}{l}\text { Gebrek aan ouerlike dissipline, } \\
\text { beheer en/of liefde by die } \\
\text { ouerhuis }\end{array}$ & 27 & 10,4 & 215 & 82.7 & 17 & 6,5 & 1 & 0,4 \\
\hline $\mathrm{b}$ & Enkelgesinne (moeder of vader) & 3 & 1,2 & 203 & 78,7 & 49 & 19.0 & 3 & 1,2 \\
\hline $\mathrm{c}$ & $\begin{array}{l}\text { Onderlinge watardeverskille } \\
\text { tussen ouers }\end{array}$ & 8 & 3,1 & 160 & 62.7 & 83 & 32,5 & 4 & 1,6 \\
\hline d & 'n Swak selfbeeld by die leerling & 10 & 3,9 & 156 & 60.9 & 87 & 34,0 & 3 & 1,2 \\
\hline e & $\begin{array}{l}\text { Prestasiedruk van sy ouder- } \\
\text { domsgroep }\end{array}$ & 4 & 1,6 & 109 & 42.4 & 137 & 53,3 & 7 & 2,7 \\
\hline $\mathrm{f}$ & Prestasiedruk van sy ouers & 9 & 3,5 & 122 & 47,5 & 123 & 47,9 & 3 & 1,2 \\
\hline g & $\begin{array}{l}\text { Oorbevolking in sekere huise } \\
\text { (bv. gesinne wat noodgedwonge } \\
\text { saamwoon) }\end{array}$ & 8 & 3,1 & 61 & 23,9 & 140 & 54.9 & 46 & 18,0 \\
\hline $\mathbf{h}$ & $\begin{array}{l}\text { Omgewingsfaktore soos woon- } \\
\text { gebied, leefwyse, opvoedling, } \\
\text { kwalifikasies }\end{array}$ & 12 & 4,7 & 125 & 48,6 & 107 & 41,6 & 13 & 5,1 \\
\hline i & $\begin{array}{l}\text { Blootstelling aan misdaad en } \\
\text { geweld }\end{array}$ & 13 & 5,1 & 69 & 27,2 & 140 & 55,1 & 32 & 12,6 \\
\hline j & Gebrek aan studeerplek & 4 & 1,6 & 66 & 25,9 & 162 & 63,5 & 23 & 9,0 \\
\hline k & $\begin{array}{l}\text { Onpersoonlikheid op skool } \\
\text { (groot klasse, geen persoonlike } \\
\text { kontak) }\end{array}$ & 3 & 1,2 & 42 & 16.4 & 138 & 53,9 & 73 & 28,5 \\
\hline 1 & $\begin{array}{l}\text { Onbuigsame, onsimpatieke en } \\
\text { onsensitiewe gesindhede van } \\
\text { onderwysers }\end{array}$ & 6 & 2,3 & 37 & 14,5 & 160 & 62,5 & 53 & 20 \\
\hline
\end{tabular}


By 'n ontleding van die response in Tabel 1(a)-(c) blyk dit dat die respondente van mening is dat die stand van sake binne die ouerhuis as die vernaamste oorsaak vir die ongedissiplineerdheid van die leerlinge op skool bestempel kan word. Hierdie respons stem grootliks ooreen met soortgelyke opnames wat in die VSA gemaak is (Hyman \& D'Alessandro, 1984:42; Reed, 1983:77).

Tabel 2 Motiewe by straf

\begin{tabular}{|l|l|r|l|l|l|l|l|l|l|}
\hline & Motiewe by straf & \multicolumn{2}{|l|}{ Altyd } & \multicolumn{2}{l|}{ Dikwels } & \multicolumn{2}{l|}{ Selde } & \multicolumn{2}{l|}{ Nooit } \\
\hline & & $\mathbf{f}$ & $\%$ & $\mathbf{f}$ & $\%$ & $\mathbf{f}$ & $\%$ & $\mathbf{f}$ & $\%$ \\
\hline a & Vergelding & 7 & 2,8 & 2 & 0,8 & 27 & 11,0 & 210 & 85,4 \\
\hline b & $\begin{array}{l}\text { Toekomstige verbetering van } \\
\text { die leerling }\end{array}$ & 135 & 52,1 & 58 & 22,4 & 54 & 20,8 & 12 & 4,6 \\
\hline c & $\begin{array}{l}\text { Afskrikmiddel vir toekomstige } \\
\text { oortredings }\end{array}$ & 35 & 14,0 & 77 & 30,8 & 96 & 38,4 & 42 & 16,8 \\
\hline
\end{tabular}

Dit blyk uit Tabel 2 dat ' $n$ groot persentasie van die respondente die leerlinge tug met die oog op die toekomstige verbetering van die leerlinggedrag. Hierdie benaderingswyse strook met die opvoedende onderwysbenadering van toekomsgerigtheid (Oosthuizen \& Bondesio, 1988:72) wat nie alleen daarop gerig is om die opvoedeling tot moontlike loopbaangereedheid te omvorm nie, maar ook om hom na verantwoordelike volwassenheid te begelei.

TABEL 3 Verbale tugmaatreëls

\begin{tabular}{|l|l|r|r|r|r|r|r|r|r|}
\hline & $\begin{array}{l}\text { Vorme van verbale } \\
\text { tugmaatreëls }\end{array}$ & \multicolumn{2}{l|}{ Altyd } & \multicolumn{2}{l|}{ Dikwels } & \multicolumn{2}{l|}{ Selde } & \multicolumn{2}{l|}{ Nooit } \\
\hline & & $\%$ & $f$ & $\%$ & $f$ & $\%$ & f & $\%$ \\
\hline a & Klanksillabes (bv. sjuut) & 2 & 0,8 & 49 & 20,4 & 93 & 38,8 & 96 & 40,0 \\
\hline b & Stemvolume & 14 & 5,5 & 138 & 54,3 & 81 & 31,9 & 21 & 8,3 \\
\hline c & Stemtoon & 34 & 13,3 & 194 & 76,1 & 24 & 9,4 & 3 & 1,2 \\
\hline d & Spraaktempo & 16 & 6,3 & 150 & 58,8 & 74 & 29.0 & 15 & 5,9 \\
\hline e & Sarkasme & 1 & 0,4 & 10 & 4,0 & 89 & 35,3 & 152 & 60,3 \\
\hline f & Humor wat as vernaning dien & 7 & 2,8 & 175 & 68,9 & 63 & 24,8 & 9 & 3,5 \\
\hline g & Verbale bestraffing & 11 & 4,3 & 221 & 86,7 & 22 & 8,6 & 1 & 0,4 \\
\hline
\end{tabular}


1.J. Oosthuizen

\begin{tabular}{|l|l|c|c|c|c|c|c|c|c|}
\hline $\mathrm{h}$ & Berisping & 15 & 5,9 & 222 & 86,7 & 15 & 5,9 & 4 & 1,6 \\
\hline $\mathrm{i}$ & $\begin{array}{l}\text { Blote dreigemente sonder } \\
\text { optrede }\end{array}$ & 1 & 0,4 & 31 & 12,2 & 128 & 50,4 & 94 & 37,0 \\
\hline $\mathrm{j}$ & Onbeheersde woede & 0 & 0 & 1 & 0,4 & 42 & 16,5 & 211 & 83,1 \\
\hline $\mathrm{k}$ & Skreeu & 0 & 0 & 1 & 0,4 & 27 & 10,7 & 225 & 88,9 \\
\hline $\mathrm{I}$ & Rapportering van 'n leerling & 13 & 6,0 & 76 & 34,9 & 81 & 37,2 & 48 & 22,0 \\
\hline $\mathrm{m}$ & Isolering (afsondering) & 0 & 0 & 8 & 3,1 & 61 & 23,6 & 189 & 73,3 \\
\hline $\mathrm{n}$ & $\begin{array}{l}\text { Ontneem van voorregte (bv. 'n } \\
\text { opvoedkundige uitstappie) }\end{array}$ & 3 & 1,2 & 20 & 7,8 & 82 & 31,8 & 153 & 59,3 \\
\hline 0 & Skoolsit & 0 & 0 & 5 & 1,9 & 46 & 17,8 & 207 & 80,2 \\
\hline $\mathrm{p}$ & $\begin{array}{l}\text { Tydelike skorsing van 'n } \\
\text { aktiwiteit (bv. rugbywedstryd) }\end{array}$ & 1 & 0,4 & 6 & 2,3 & 83 & 32,3 & 167 & 65,0 \\
\hline $\mathrm{y}$ & Strafwerk & 1 & 0,4 & 35 & 13,6 & 106 & 41,2 & 115 & 44,7 \\
\hline $\mathrm{r}$ & $\begin{array}{l}\text { Nie-verbale seine (bv. direkte } \\
\text { oogkontik) }\end{array}$ & 26 & 10,0 & 184 & 70,8 & 37 & 14,2 & 13 & 5,0 \\
\hline $\mathrm{s}$ & $\begin{array}{l}\text { Telefoniese gesprek met ouers } \\
\text { van kind }\end{array}$ & 17 & 6,5 & 180 & 69,0 & 59 & 22,6 & 5 & 1,9 \\
\hline
\end{tabular}

By die verbalisering van algemene tugmaatreëls (vergelyk Tabel 3(a)-(l)) blyk dit dat die respondente voorkeur gee aan die meer liefdevolle wyses van teregwysing walaronder die volgende tegnieke as die vemaamstes uitgewys is: berisping $(92,6 \%)$, verbale bestraffing $(91 \%)$, die verandering van stemtoon $(89,4 \%)$, die gebruikmaking van humor wat as vermaning dien $(71,1 \%)$, die wysiging van spraaktempo $(65,1 \%)$ en die verhoging van stemvolume $(59,8 \%)$. Hierdie navorsing toon dan ook alan dat die gebruik hier ter plaatse ooreenstem met die uitoefening van tug in die VSA. Brown en Payne (1988:301) het naamlik aangetoon dat verbale bestrafting die mees algemene metode is wat deur onderwysers gebruik word by die toepassing van algemene tugmaatreëls in openbare skole in die VSA.

'Tugmetodes wat opvoedkundig minder aanvaarbaar is, soos die gebruikmaking van sarkasme $(4,4 \%)$ en die uitbarsting in onbeheersde woedebuie $(0,4 \%)$ word in 'n veel mindere mate deur respondente van die Transvalalse primêre skole gebruik. 
Algemene tugmaatreëls in primêre skole

Tabel 4 Leerlinggesindheid by uitoefening van algemene tugmaatreëls

\begin{tabular}{|l|l|r|r|r|r|r|r|r|r|}
\hline & $\begin{array}{l}\text { Leerlinggesindheid by uit- } \\
\text { oefening van tugmaatreëls }\end{array}$ & \multicolumn{2}{|l|}{ Altyd } & \multicolumn{2}{l|}{ Dikwels } & \multicolumn{2}{l|}{ Selde } & \multicolumn{2}{l|}{ Nooit } \\
\hline & & f & $\%$ & f & $\%$ & f & $\%$ & f & $\%$ \\
\hline a & Aanvaarding & 95 & 36.4 & 163 & 62.5 & 3 & 1,1 & 0 & 0 \\
\hline b & Parnantigheid & 2 & 0,8 & 7 & 2,7 & 181 & 69,6 & 70 & 26,9 \\
\hline c & Opstandigheid & 1 & 0,4 & 6 & 2,3 & 191 & 73,5 & 62 & 23,8 \\
\hline d & Aggressiwiteit & 1 & 0,4 & 4 & 1,5 & 166 & 63,8 & 89 & 34,2 \\
\hline e & Traak-my-nie-agtigheid & 0 & 0 & 21 & 8,1 & 197 & 75,8 & 42 & 16,2 \\
\hline f & Emosieloosheid & 0 & 0 & 17 & 6,6 & 195 & 75,9 & 44 & 17,1 \\
\hline
\end{tabular}

Uit Tabel 4 blyk dit dat die leerlinge wat aan algemene tugmaatreëls onderwerp word, dit feitlik sonder uitsondering $(98,9 \%)$ met 'n groot mate van gelatenheid aanvaar (Tabel 4(a)). Negatiewe reaksies soos parmantigheid, opstandigheid en traak-my-nie-agtigheid ten opsigte van die uitoefening van algemene tugmaatreëls, word baie selde by leerlinge waargeneem (Tabel 4(b)-(e)).

\section{Gevolgtrekkings}

$\mathrm{Na}$ aanleiding van die voorafgaande kan sekere evaluerende afleidings gemaak word. Die bevindinge en gevolgtrekkings het uiteraard net op die gewone of normale opvoedende onderwyssituasie betrekking. Ander tugmaatreëls soos lyfstraf en skorsing sal meer toepaslik wees by 'onminsituasies' waar emstiger oortredings ter sprake is.

Die toepassing van tugmaatreëls binne die opvoedende onderwys behoort binne die gees van toekomsgerigte vorming van die leerling volvoer te word - vorming wat gepaard gaan met 'n motief van verbetering van die leerling (in plaas van byvoorbeeld 'n motief van vergelding). Die oorwegende motief van die respondente val binne die kader van hierdie nome as daarop gelet word dat hul motiewe by die uitoefening van tugmaatreëls wel die toekomstige verbetering van die leerlinge is (Tabel 2(b)). 'n Verdere ondersteuning vir hierdie afleiding kan gevind word in die feit dat die respondente hoofsaaklik gebruik maak van minder kwetsende vorme van algemene tugmaatreëls soos verbale of mondelinge bestraffing (Tabel 3(g)), berisping (Tabel 3(h)) en die aanwending van stemtoon (Tabel 3(c)) in teenstelling met byvoorbeeld die afbrekende gebruikmaking van sarkasme (Tabel 3(e)) en onbeheersde woede (Tabel 3(j)). By die nie-verbale tugmaatreëls (Tabel 3(m)-(s)) kan dieselfde tendens onderskei word: hier maak die respon- 
dente ook meer gebruik van positief-vormende tugmaatreëls soos nie-verbale seine (byvoorbeeld oogkontak) (Tabel 3(r)) en telefoniese skakeling met die besondere ouers (Tabel 3(s)) in teenstelling met die krasser en afbrekende tugmaatreëls soos skoolsit (Tabel 3(o)), die tydelike skorsing van 'n aktiwiteit (Tabel $3(\mathrm{p})$ ), die isolering van ' $\mathrm{n}$ oortreder (Tabel $3(\mathrm{~m})$ ) en die ontneem van voorregte van die oortreder (Tabel 3(n)).

Dit wil voorkom asof daar ' $n$ verband kan bestaan tussen positief opbouende optrede en die gesindheid van die respondente by die uitoefening van algemene tugmaatreëls en die leerlinge se positiewe aanvaarding daarvan (Tabel 4(a)). Die respondente se waameming is naamlik dat die leerlinge die uitoefening van algemene tugmaatreëls feitlik deurgaans positief aanvaar in teenstelling met negatiewe reaksies soos opstandigheid (Tabel 4(c)), parmantigheid (Tabel 4(b)) of aggressiwiteit (Tabel 4(d)) wat in 'n baie geringe mate deur leerlinge geopenbaar word.

\section{Aanbevelings}

Uit die voorafgaande bevindings kan die volgende aanbevelings gemaak word:

Aangesien die dissiplinêre klimaat in die ouerhuis en die skool hand aan hand gaan, behoort die ouerhuis, wat as die vernaamste bron van leerlingongedissiplineerdheid beskou word, betrek te word. In die eerste plek behoort ouerhuise ingelig te word by geleenthede soos oueraande, ouerverenigingvergaderings en deur middel van inligtingskrywes, van die nasionale sowel as internasionale empirie ten opsigte van die ouerhuis se rol by ongedissiplineerde leerlinggedrag. Vervolgens behoort die onderwerp van dissiplinering by oueraande behandel te word. Daar moet gepoog word om binne die klimaat van 'n besondere kulturele milieu samewerking te verkry tussen ouer en onderwyser om die gehalte van leerlinggedissiplineerheid te verbeter en te standaardiseer.

Aangesien die verskillende wyses van algemene tughandhawing (verbaal en nieverbaal) as besonder bruikbaar uitgewys is, moet dit verder verfyn en bestudeer word. Onderwysersopleidingsinstansies behoort daarvan kennis te neem en die onderskeie tughandhawingstegnieke by hul onderrigmateriaal in te sluit.

\section{Samevatting}

Waar die modene wêreld hom in die greep van ordeloosheid en ongedissiplineerdheid bevind, bly die opvoedende onderwys nie onaangeraak nie. Orde binne die opvoedende onderwys is egter een van die hoekstene van die opvoedende onderwyssituasie. Ouer en onderwyser sal met die bewese empiriese gegewens as uitgangspunt die probleem in die oë moet staar en 'n sinvolle praktyk daarvoor moet uitwerk.

Koers 58(2) 1993:211-218 


\section{Bibliografie}

ALTERN, J. 1992. Seun kry R2 000 skadevergoeding vir pyn en lyding ná oordrewe pak slae. Beeld:1, Mei 16.

BAKER, K. 1985. Research Evidence of a School Discipline Problem. Phi Delta Kappan, $66(7): 486$.

BAUER, G.L. 1985. Restoring Order to the Public Schools. Phi Delta Kappan, 66(7):489.

BAYLISS, W.A. 1992. 'n Evaluering van tugmaatreëls in Transvaalse primêre skole. Potchefstroom : PU vir CHO. (Verhandeling - M.Ed.)

BROWN, W.E. \& PAYNE, T. 1988. Policies/Practices in Public School Discipline. Academic Therapy, 23(3):297.

GRIESSEL, G.A.J. 1975. Die gesagsverhouding in opvoedingsleer-perspektief en fundamentele pedagogiek-perspektief. Pretoria : Unisa. (Proefskrif - D.Ed.)

HEYNS, J.A. 1989. Teologiese etiek 2/2: sosiale etiek. Pretoria : N.G. Kerkboekhandel.

HYMAN, I.A. \& D'ALESSANDRO, J. 1984. Good Old-Fashioned Discipline. The Politics of Punitiveness. Phi Delta Kappan, 66(1):39-43, September.

LEWIS. R. \& LOVEGROVE. M. 1984. Teachers' Classroom Control Procedures: Are Students' Preferences Being Met? Journal of Education and Teaching, 10(2):97105.

OOSTHUIZEN, I.J. \& BONDESIO, M.J. 1988. Die reg in die onderwyspraktyk. Pretoria : Academica.

REED. R.J. 1983. Administration's Advice: Causes and Remedies of School Conflict and Violence. NASSP Bulletin, 67(462):77

SHRIGLEY, R.L. 1986. Teacher Authority in the Classroom: A Plan for Action. NASSP Bulletin, 70(490):65.

SUID-AFRIKAANSE HOFVERSLAE : $S v$ Lekgathe 19823 SA 104 (BT)

SUID-AFRIKAANSE HOFVERSLAE : $S$ v Meeuwis 19704 SA 532 (T)

SUID-AFRIKAANSE HOFVERSLAE : Rex $v$ Muller 19484 SA 848 (O)

SUID-AFRIKAANSE HOFSAAK (ongerapporteer) : John Buckingham v Die Minister van Ondernys en Kultuur. 1992. 